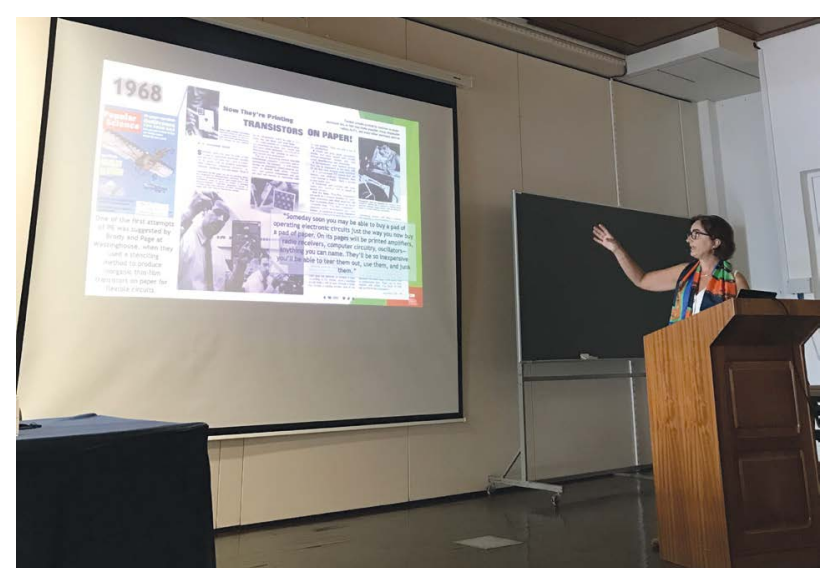

Lição plenária da Prof. ${ }^{a}$ Elvira Fortunato.

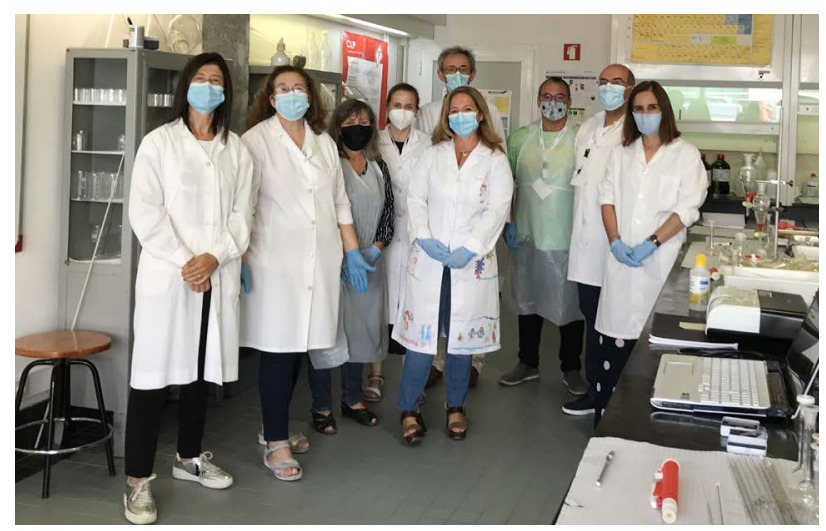

Participantes na oficina "Extração e

doseamento da cafeína em bebidas energéticas.

A bebida TOP! TOP! TOP! entre os adolescentes!".
"Fenómenos óticos atmosféricos e outros meteoros", "Visita guiada ao modelo padrão das partículas elementares", "A física à escuta da Terra", "O Sol, a fonte de energia que move o nosso mundo", "Propriedades e movimento de fluidos - vamos falar de nascentes hídricas", "Smartphone: laboratório portátil de física experimental", "Mãos às argamassas", "Doseamento do açúcar em bebidas refrigerantes. Simples, seguro e sustentável!", "Polímeros sintéticos e naturais no laboratório", "Química em jogos de tabuleiro", "Química forense", "Têxteis à lupa", "Frutos antioxidantes e sua importância numa alimentação saudável" e "Extração e doseamento da cafeína em bebidas energéticas. A bebida TOP! TOP! TOP! entre os adolescentes".

A Comissão Organizadora agradece a todas as pessoas e entidades que colaboraram, tornando possível o sucesso deste Encontro, nomeadamente, os patrocinadores e instituições que o apoiaram e/ ou estiveram presentes. Uma palavra de reconhecido agradecimento é devida também à Sociedade Portuguesa de Física e à Universidade de Évora que cedeu os espaços e recursos necessários. Por último, um agradecimento a todos os participantes pois sem eles este Encontro não faria sentido.

Mais informações sobre o Encontro podem ser consultadas em 8enpfq.sci-meet.net.

Margarida Figueiredo

mtf@uevora.pt
Cristina Galacho

pcg@uevora.pt

\section{Manuel João Monte e Sofia Miguens com Novo Livro Apoiado pela SPQ}

A nova peça da autoria de Manuel João Monte e Sofia Miguens, Que Coisa é o Mundo (O Estado Dogmático), acaba de ser lançado no passado mês de agosto. A sessão de autógrafos teve lugar a 5 de setembro na Feira do Livro do Porto. Editado pela U. Porto Press, e apoiado pela SPQ, Que Coisa é o Mundo coloca várias questões sobre a nossa origem e a nossa dimensão. "Quem somos nós? Seremos apenas um conjunto de átomos e moléculas? E os vírus são ou não seres vivos?

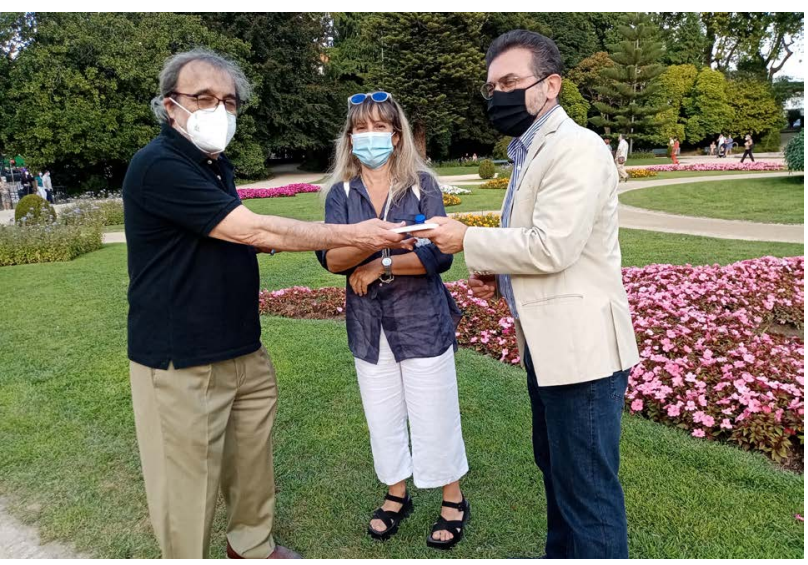

A SPQ recebe das mãos dos autores um

exemplar da peça, nos Jardins do antigo Palácio de Cristal, por ocasião da sessão de autógrafos da Feira do Livro do Porto, 5 de setembro, 2021. Da esquerda: Manuel João Monte e Sofia Miguens (autores), Joaquim Luís Faria (Vice-Presidente da SPQ). 
(...) são dúvidas que um Presidente de um hipotético país quer ver respondidas (...)".

A peça em dois atos reúne um conjunto de sete personagens que nos remetem para o nosso coletivo histórico-cultural, alternado entre a sala de reuniões de uma comissão imaginária e um bar nas suas redondezas. 0 estilo produz vários diálogos ligeiros, sobre temas complexos e atuais, importantes, ou não tão importantes, mas que sobretudo atraem pela forma envolvente como progridem ao longo do texto. Aliás, nas palavras do autor, a melhor maneira de trazer os jovens de hoje para a leitura é precisamente "através de diálogos soft, livros com poucas páginas, leitura entusiasmante, concisa e com algum humor (como faziam os antigos filósofos g'regos)." (in Química 161, 2021). A receita resulta, e ao longo das cerca de 160 páginas, os autores transportam-nos num filosofar agradável e relaxante, que convidará à reflexão na medida própria de cada um.

Manuel João Monte foi professor associado do Departamento de Química e Bioquímica da Faculdade de Ciências da Universidade do Porto. Jubilado em agosto de 2019, goza atualmente do estatuto de professor associado convidado. Publicou mais de 100 artigos em revistas científicas internacionais na área da
Termodinâmica e traduziu para português duas peças de Carl Djerassi (e Roald Hoffmann). Em 2019 escreveu a peça de teatro 0 Bairro da Tabela Periódica, editada pela Universidade do Porto (coleção Fora de Série, n. ${ }^{\circ}$ 1) com o apoio da SPQ, que foi levada à cena em Oeiras, Coimbra e Porto pela companhia Marionet, no âmbito do programa nacional da SPQ relativo ao Ano Internacional da Tabela Periódica. Em 2020 publicou uma segunda peça também com o apoio da SPQ, Arsenicum, U. Porto Press (coleção Fora de Série, n. ${ }^{\circ} 4$ ).

Sofia Miguens é professora catedrática do Departamento de Filosofia da Faculdade de Letras e investigadora do Instituto de Filosofia da Universidade do Porto, onde fundou em 2005 o Mind, Language and Action Group (MLAG), que dirige. As suas áreas de investigação são a Filosofia da Mente e da Linguagem, a Epistemologia e Ciência Cognitiva, a Filosofia Moral e a História da Filosofia Contemporânea. É autora de sete livros e de mais de uma centena de artigos publicados em revistas da especialidade.

\section{Joaquim Luís Faria}

jlfaria@fe.up.pt

\section{Prémio Nobel da Química 2021 Atribuído a Benjamin List e David MacMillan}

A Academia Real das Ciências da Suécia atribuiu o Prémio Nobel da Química de 2021 ao alemão Benjamin List e ao escocês David W. C. MacMillan pelo "desenvolvimento da organocatálise assimétrica", uma "engenhosa ferramenta para a construção de moléculas".

Benjamin List, do Max Planck Institute for Coal Research (Alemanha) e David W. C. MacMillan, da Universidade de Princeton (EUA), desenvolveram a organocatálise assimétrica de forma independente em 2000. Este terceiro ramo da catálise, à qual se juntam a catálise por metais e a catálise enzimática, não só tornou a química mais verde, como também facilitou a produção de moléculas assimétricas e tem, desde então, conhecido desenvolvimentos importantes. List e MacMillan permanecem líderes nesta área, demostrando a importância da organocatálise no desenvolvimento de novas moléculas para as mais diferentes aplicações e novos métodos de síntese.

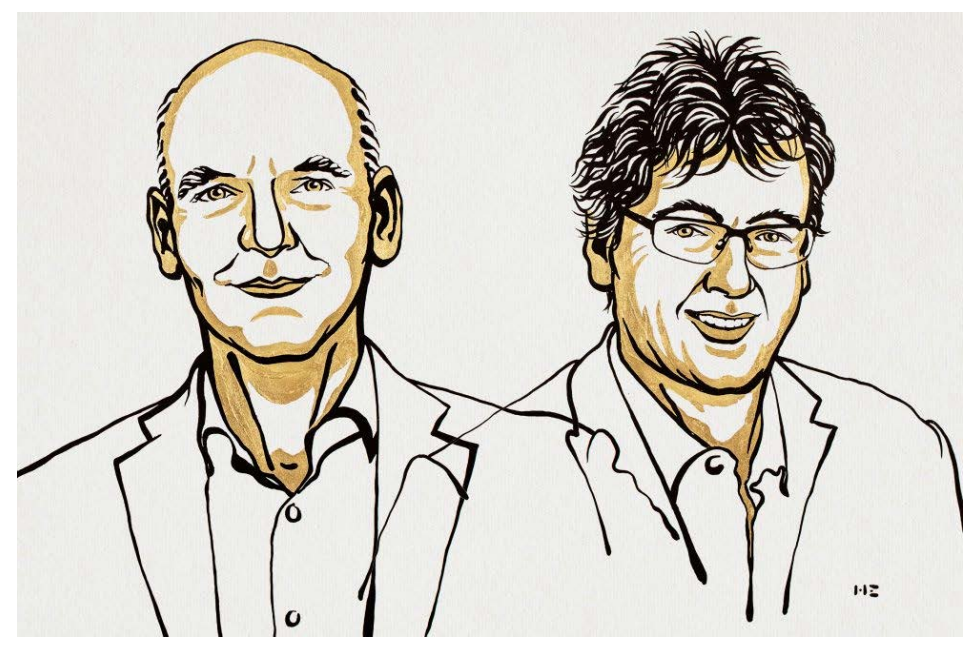

Benjamin List (à esquerda) e David MacMillan (à direita). Niklas Elmehed ๔ Nobel Prize Outreach.

Mais informações sobre a atribuição do prémio em nobelprize.org/prizes/chemistry/2021/summary.

Bruno Machado

brunofm@fe.up.pt 